\title{
Is the air in Toronto, Rochester, and Cleveland different from that in London, Monaco, Leiden, Genk, Milan, and New York?
}

\author{
Robert A. Dion, MD
}

\begin{abstract}
The tricuspid valve has been recently referred to as the "forgotten valve," because one now realizes that tricuspid regurgitation is bad for the patient and that reoperation for progressive tricuspid regurgitation after a left-sided valvular correction still carries a high mortality risk. However, the indication for concomitant tricuspid valve repair during a mitral valve repair procedure is still controversial, as illustrated by the reaction of Dr T. David to the presentation of Dr Chikwe and colleagues at the 2015 American Association for Thoracic Surgery meeting. One of the explanations for these divergent opinions could be that tricuspid regurgitation grading is largely unreliable because of the dependence of the right ventricle on the preload and of the discrepancy between clinical and hemodynamic data. Therefore, we need a parameter that does not depend on preload. An annular dilation of $40 \mathrm{~mm}$ or $21 \mathrm{~mm} / \mathrm{m}^{2}$ has been proposed and validated by many authors. The preoperative functional class also plays a major role. Tricuspid regurgitation is a progressive disease, but the presence of a concomitant mitral valve disease may aggravate annular dilation; therefore, the earlier we operate on the mitral valve, the less frequently patients will require concomitant tricuspid valve repair. (J Thorac Cardiovasc Surg 2015;150:1040-3)
\end{abstract}

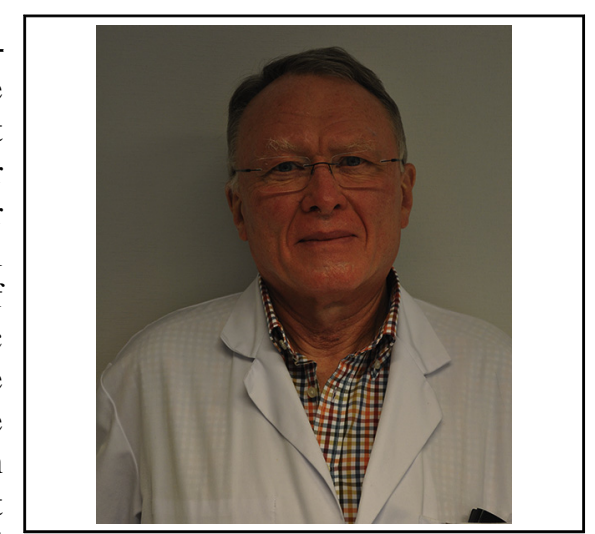

Robert A. Dion, MD

\section{Central Message}

Concomitant functional TR: Repair before irreversible annular dilatation $(\geq 40 \mathrm{~mm}$ or $\left.21 \mathrm{~mm} / \mathrm{m}^{2}\right)$. This is also a plea for early mitral surgery.

\section{Perspective}

The indication of concomitant TVr, based on annular dilation rather than on TR grading, during an MV procedure is supported by an increasing number of authors but still challenged by others. The earlier the MV procedure, the less frequent concomitant TVr. In any case, there is a definite agreement to avoid reoperation on the TV after an MV procedure.

See Editorial Commentaries page 1043 and 1045 .
At the 2015 American Association for Thoracic Surgery Annual Meeting in Seattle, Chikwe and colleagues ${ }^{1}$ presented the comparative outcomes of an aggressive strategy of tricuspid valve repair (TVr) concomitant to mitral valve (MV) repair in degenerative disease whenever moderate tricuspid regurgitation (TR) or tricuspid annular

From the Department of Cardiac Surgery, Ziekenhuis Oost-Limburg, Genk, Belgium. Received for publication June 22, 2015; revisions received Aug 4, 2015; accepted for publication Aug 14, 2015; available ahead of print Sept 22, 2015.

Address for reprints: Robert A. Dion, MD, Department of Cardiac Surgery, Ziekenhuis Oost-Limburg, Genk, Belgium (E-mail: robert.dion@zol.be). 0022-5223/\$36.00

Copyright (c) 2015 by The American Association for Thoracic Surgery http://dx.doi.org/10.1016/j.jtcvs.2015.08.048 dilatation (TAD) $(\geq 40 \mathrm{~mm})$ was present. This led to a concomitant TVrin approximately two thirds of the patients.

The strategy was validated because there was no significant difference in mortality, morbidity, or permanent pacemaker requirement; it durably cured $\mathrm{TR}$, prevented progression of $\mathrm{TR}$ at the 7-year follow-up, induced right ventricle (RV) recovery, and reduced pulmonary hypertension (PHT).

In his discussion of the article, Dr Tirone David called this strategy "an overkill." In his 30-year experience with MV repair, he has not seen a significant progression of TR in patients, even in the presence of an advanced myxomatous degeneration, noting "less than $10 \%$ of the patients developed significant TR at 25 years." In his opinion, the use of a rigid ring in MV repair is the cause of TR development. He also commented that "the $40 \mathrm{~mm}$ diameter threshold 

Abbreviations and Acronyms
$\mathrm{TVr}=$ tricuspid valve repair
$\mathrm{MV}=$ mitral valve
$\mathrm{TR}=$ tricuspid regurgitation
$\mathrm{TAD}=$ tricuspid annular dilatation
$\mathrm{RV}=$ right ventricle
PHT $=$ pulmonary hypertension
$\mathrm{LV}=$ left ventricle
$\mathrm{TA}=$ tricuspid annulus
$\mathrm{AL}=$ anterior leaflet
SL $=$ septal leaflet
$\mathrm{PL}=$ posterior leaflet

has not been validated in patients with degenerative mitral valve disease."

I will address his 2 last assertions about rigid rings in the mitral position and the $40-\mathrm{mm}$ diameter threshold. There is no evidence linking the rigidity of the mitral ring and the development or progression of TR. Dr David had to admit that pliable rings were becoming more and more rigid with time, and as early as 6 months because of the formation of scar tissue. In addition, a pliable ring is not dilating in diastole.

Progressive tricuspid annular dilation in the setting of mitral regurgitation was alluded to as early as 1974 by Carpentier and colleagues ${ }^{2}$ ( 3 fingers) and later by Sagie and colleagues, ${ }^{3}$ Fukuda and colleagues, ${ }^{4}$ Tager and colleagues, ${ }^{5}$ Colombo and colleagues, ${ }^{6}$ Sugimoto and colleagues, ${ }^{7}$ and Kim and colleagues. ${ }^{8}$ Most of them were already proposing $40 \mathrm{~mm}$ as the threshold to perform a concomitant $\mathrm{TVr}$, and many of their patients had no rheumatic valve disease.

The rationale behind considering annular dilation rather than TR grading rests on 3 points: (1) TR grading is largely unreliable because the RV is eminently dependent on preload, and annular dilation is not; (2) there is a discrepancy between clinical and hemodynamic data ${ }^{9,10}$; and (3) TR is bad for the patient. ${ }^{11}$

In fact, the $7 \mathrm{~cm}$ intraoperatively measured by Dreyfus and colleagues ${ }^{12}$ between the commissures anterior leaflet $(\mathrm{AL}) /$ septal leaflet $(\mathrm{SM})$, and $\mathrm{AL} /$ posterior leaflet $(\mathrm{PL})$ also correspond to the $4 \mathrm{~cm}$ (mid AL-mid SL) measured by echocardiography; most of the patients in the study by Dreyfus and colleagues ${ }^{12}$ had degenerative disease. Therefore, I proposed the 40-mm threshold, and it was adopted while I was a member of the European Guidelines Taskforce in 2006. ${ }^{13}$ This was taken over in the American Guidelines. ${ }^{14}$ The $40-\mathrm{mm}$ threshold has been further validated by De Bonis and colleagues, ${ }^{15}$ Goldstone and colleagues, ${ }^{16}$ and Benedetto and colleagues. ${ }^{17}$ During my stay in Leiden, Van de Veire and colleagues ${ }^{18}$ found the same protective effect of an aggressive strategy on TR progression, RV function, and PHT, and again in Genk. ${ }^{19}$ The same conclusions were recently reached by Desai and colleagues $^{20}$ and Kilic and colleagues. ${ }^{21}$ The Society of Thoracic Surgeons database even indicates a lower risk if TR valve surgery is added to MV surgery.

Similar to David's approach, Yilmaz and colleagues ${ }^{22}$ at the Mayo Clinic reported a conservative approach to concomitant $\mathrm{TVr}$, but $30 \%$ of their patients had at least moderate TR after 5 years despite the preoperative exclusion of patients with PHT, RV dysfunction, or failure.

At the present time, concomitant tricuspid repair is performed in $7 \%$ to $10 \%$ of patients at the Mayo Clinic and in Toronto (T. David); in 25\% of patients in Leipzig (F. Mohr); in $40 \%$ to $45 \%$ of patients in Monaco (G. Dreyfus), Leiden, and Genk (R. Dion); and in $65 \%$ of patients in New York (D. Adams).

Gillinov, the invited discussant of the Chikwe article at the American Association for Thoracic Surgery, would only repair TV if the TR is "moderate," but what does "moderate" mean?

What could be the reasons for such divergent opinions regarding the importance of concomitant $\mathrm{TVr}$ at the time of MV repair?

First, the preoperative functional class certainly plays a major role. On one side of the spectrum, as noted by Dr Adams in the discussion of the article, patients in New York Heart Association class III and IV (as in presumably many patients of the historical cohort of Dr David) who did not develop at least moderate TR at the time of the mitral procedure will likely not do so after MV repair. On the other side of the spectrum, asymptomatic patients with normal left ventricle (LV) and no or mild TR (as in presumably the majority of the current patients of Dr David) are less likely to develop severe TAD. In an ongoing prospective study, De Bonis and colleagues ${ }^{15}$ (San Raffaele, Milano) found a $40 \mathrm{~mm}$ or greater TAD in only $5.3 \%$ of the patients undergoing early MV repair with TR 2 or less. The earlier we operate on the MV, the less frequently patients will require $\mathrm{TVr}$.

Second, measurement of the TV diameter is not really standardized. In view of the triangular shape of the tricuspid valve, it should be measured precisely between the midpoints of the anterior and septal annular segments. By using 2-dimensional echocardiography, according to Berrebi, ${ }^{23}$ Carpentier's echocardiographist, it should be measured in diastole on a 4-chamber view with the echocardiography beam cutting the MV through A3-P3. Of course, the measure is easier if one uses 3-dimensional echocardiography or magnetic resonance imaging. A large circular but still competent $\mathrm{TV}$ is probably prone to develop TR in the future, because the leaflets are made for a triangular-shaped annulus.

Third, the type of approach to the MV probably makes a difference, that is, a transseptal approach automatically exposes the tricuspid valve. 


\section{WHERE DO I STAND NOW IN MY OWN PRACTICE?}

I systematically use a transseptal approach of the MV.

1. TR 2 or greater: TVr using a remodeling semi-rigid ring sized on the area of the anterior leaflets tissue; TR 2 or greater + tenting distance $8 \mathrm{~mm}$ or greater: TVr includes augmentation of the anterior leaflet.

2. TR less than 2, tricuspid annulus (TA) $40 \mathrm{~mm}$ or greater (or $21 \mathrm{~mm} / \mathrm{m}^{2}$ ): TVr.

3. TR less than 2, TA greater than 3.5 and less than $4.0 \mathrm{~mm}$.

In the presence of atrial fibrillation, rheumatic heart disease,

PHT,

RV dysfunction,

TV leaflets coaptation less than $3 \mathrm{~mm}$, dilated cardiomyopathy, and

LV dysfunction

An impaired diastolic and/or systolic LV function needs optimal filling from the right side of the heart ...

Otherwise, abstention.

4. Any doubtful presentation or presence of transvalvular pacemaker lead: systematic surgical inspection.

The major issue is to do everything possible to avoid the risk and outcomes of reoperative tricuspid valve surgery, as recently noted by Jeganathan and colleagues, ${ }^{24}$ with an in-hospital mortality of $13.2 \%$, and Pfannmüller and colleagues, ${ }^{25}$ with an in-hospital mortality of $14.6 \%$, despite their extensive experience and high skills.

I want to underline that the proposed aggressive approach proposed will not completely prevent the spontaneous evolution of TR even after an early and successful MV repair as demonstrated by Dreyfus and colleagues. ${ }^{12}$

Dr Gilinov and others advocate a prospective randomized trial, but then I would already propose to definitely exclude patients with LV dysfunction, RV dilation/dysfunction, atrial fibrillation, PHT, rheumatic heart disease, dilated cardiomyopathy, pacemaker leads, and a TA diameter of less than 3.5 or greater than $4.5 \mathrm{~cm}$.

\section{Conflict of Interest Statement}

Dr Dion reports consulting fees from Sorin, Edwards, Johnson \& Johnson, and St. Jude Medical.

\section{References}

1. Chikwe J, Itagaki S, Anyanwu A, Adams DH. Impact of concomitant tricuspid annuloplasty on tricuspid regurgitation, right ventricular function, and pulmonary artery hypertension after repair of mitral valve prolapse. J Am Coll Cardiol. 2015;65:1931-8.

2. Carpentier A, Deloche A, Hanania G, Forman J, Sellier P, Piwnica A, et al. Surgical management of acquired tricuspid valve disease. J Thorac Cardiovasc Surg. 1974;67:53-65.
3. Sagie A, Schwammenthal E, Palacios IF, King ME, Leavitt M, Freitas N, et al. Significant tricuspid regurgitation does not resolve after percutaneous balloon mitral valvotomy. J Thorac Cardiovasc Surg. 1994;108:727-35.

4. Fukuda N, Oki T, Iuchi A, Tabata T, Yamada H, Ito S, et al. Tricuspid inflow and regurgitant flow dynamics after mitral valve replacement: differences relating to surgical repair of the tricuspid valve. J Heart Valve Dis. 1997;6: 184-8.

5. Tager R, Skudicky D, Mueller U, Essop R, Hammond G, Sareli P. Long-term follow-up of rheumatic patients undergoing left-sided valve replacement with tricuspid annuloplasty - validity of preoperative echocardiographic criteria in the decision to perform tricuspid annuloplasty. Am J Cardiol. 1998; 81:1013-6.

6. Colombo T, Russo C, Ciliberto GR, Lanfranconi M, Bruschi G, Agati S, et al. Tricuspid regurgitation secondary to mitral valve disease: tricuspid annulus function as guide to tricuspid valve repair. Cardiovasc Surg. 2001; 9:369-77.

7. Sugimoto T, Okada M, Ozaki N, Hatakeyama T, Kawahira T. Long-term evaluation of treatment for functional tricuspid regurgitation with regurgitant volume: characteristic differences based on primary cardiac lesion. J Thorac Cardiovasc Surg. 1999;117:463-71.

8. Kim HK, Kim YJ, Park JS, Kim KH, Kim KB, Ahn H, et al. Determinants of the severity of functional tricuspid regurgitation. Am J Cardiol. 2006;98: 236-42.

9. Cohn LH. Tricuspid regurgitation secondary to mitral valve disease: when and how to repair. J Card Surg. 1994;9(2 Suppl):237-41.

10. Porter A, Shapira Y, Wurzel M, Sulkes J, Vaturi M, Adler Y, et al. Tricuspid regurgitation late after mitral valve replacement: clinical and echocardiographic evaluation. J Heart Valve Dis. 1999;8:57-62.

11. Nath J, Foster E, Heidenreich PA. Impact of tricuspid regurgitation on long-term survival. J Am Coll Cardiol. 2004;43:405-9.

12. Dreyfus GD, Corbi PJ, Chand KM, Bahrami T. Secondary tricuspid regurgitation or dilatation: which should be the criteria for surgical repair? Ann Thorac Surg. 2005;79:127-32.

13. Vahanian A, Baumgartner H, Bax J, Butchart E, Dion R, Filippatos G. Guidelines on the management of valvular heart disease: the Task Force on the Management of Valvular Heart Disease of the European Society of Cardiology. Eur Heart J. 2007;28:230-68.

14. Bonow RO, Carabello BA, Kanu C, de Leon AC Jr, Faxon DP, Freed MD, et al. ACC/AHA 2006 guidelines for the management of patients with valvular heart disease: a report of the American College of Cardiology/ American Heart Association Task Force on Practice Guidelines (Writing Committee to Revise the 1998 Guidelines for the Management of Patients With Valvular Heart Disease). Circulation. 2006;114:e84-231.

15. De Bonis M, Lapenna E, Sorrentino F, La Canna G, Grimaldi A, Maisano F, et al. Evolution of tricuspid regurgitation after mitral valve repair for functional mitral regurgitation in dilated cardiomyopathy. Eur J Cardiothorac Surg. 2008;33: 600-6.

16. Goldstone AB, Howard JL, Cohen JE, MacArthur JW Jr, Atluri P, Kirkpatrick JN, et al. Natural history of coexistent tricuspid regurgitation in patients with degenerative mitral valve disease: implications for future guidelines. J Thorac Cardiovasc Surg. 2014;148:2802-10.

17. Benedetto U, Melina G, Angeloni E, Refice S, Roscitano A, Comito C, et al. Prophylactic tricuspid annuloplasty in patients with dilated tricuspid annulus undergoing mitral valve surgery. J Thorac Cardiovasc Surg. 2012;143: 632-8.

18. Van de Veire NR, Braun J, Delgado V, Delgado V, Versteegh MI, Dion RA, et al. Tricuspid annuloplasty presents right ventricular dilatation and progression of tricuspid regurgitation in patients with tricuspid annular dilatation undergoing mitral valve repair. J Thorac Cardiovasc Surg. 2011;141:1431-9.

19. Bertrand PB, Koppers G, Verbrugge FH, Mullens W, Vandervoort P, Dion R, et al. Tricuspid annuloplasty concomitant with mitral valve surgery: effects on right ventricular remodeling. J Thorac Cardiovasc Surg. 2014;147:1256-64.

20. Desai RR, Vargas Albello LM, Klein AL, Marwick TH, Krasuski RA, Ye Y, et al. Tricuspid regurgitation and right ventricular function after mitral valve surgery with or without concomitant tricuspid valve procedure. J Thorac Cardiovasc Surg. 2013;146:1126-32.

21. Kilic A, Saha-Chaudhuri P, Rankin JK, Conte JV. Trends and outcomes of tricuspid valve surgery in North America: an analysis of more than 50,000 patients from The Society of Thoracic Surgeons database. Ann Thorac Surg. 2013;96:1546-52.

22. Yilmaz O, Suri RM, Dearani JA, Sundt TM III, Daly RC, Burkhart HM, et al. Functional tricuspid regurgitation at the time of mitral valve repair for 
degenerative leaflet prolapse: the case for a selective approach. J Thorac Cardiovasc Surg. 2011;142:608-13.

23. Berrebi A, Philip I. Echocardiographie peropératoire. In: Cormier B, Lansac E, Obadia JF, Tribouilloy C, Lavoisier SAS, eds. Cardiopathies valvulaires de l'adulte. Paris: Lavoisier Médicine Sciences; 2014:382-94.

24. Jeganathan R, Armstrong S, Al-Alao B, David T. The risk and outcomes of reoperative tricuspid valve surgery. Ann Thorac Surg. 2013;95:119-25.
25. Pfannmüller B, Moz M, Misfeld M, Borger MA, Funkas AK, Garbade J, et al Isolated tricuspid valve surgery in patients with previous cardiac surgery. $J$ Thorac Cardiovasc Surg. 2013;146:841-7.

Key Words: concomitant tricuspid valve repair, functional tricuspid regurgitation, indication for tricuspid valve repair

\title{
EDITORIAL COMMENTARY
}

\section{When is tricuspid valve annuloplasty necessary during mitral valve surgery?}

\author{
Tirone E. David, MD, Carolyn M. David, BN, and Cedric Manhiolt, BSc
}

\footnotetext{
From the Divisions of Cardiovascular Surgery and Cardiology, Peter Munk Cardiac Centre, Toronto General Hospital; and University of Toronto, Toronto, Ontario, Canada

Disclosures: Authors have nothing to disclose with regard to commercial support

Received for publication July 28, 2015; accepted for publication July 29, 2015; available ahead of print Aug 28, 2015.

Address for reprints: Tirone E. David, MD, 200 Elizabeth St 4N453, Toronto, Ontario M5G 2C4, Canada (E-mail:

tirone.david@uhn.ca).

J Thorac Cardiovasc Surg 2015;150:1043-4

$0022-5223 / \$ 36.00$

Copyright (C) 2015 by The American Association for Thoracic Surgery

http://dx.doi.org/10.1016/j.jtcvs.2015.07.100
}

New functional tricuspid regurgitation (TR) following mitral valve (MV) replacement is a puzzling and an unresolved problem, particularly in patients with rheumatic disease. I used to perform tricuspid valve annuloplasty (TVA) whenever there was moderate or severe TR at the time of MV replacement. Dreyfus and colleagues ${ }^{1}$ concept that annular dilation is irreversible and precedes the occurrence of functional TR shed welcome light onto this problem. We have adopted their recommendation during MV replacement but we have not yet examined the late outcomes of this intervention in our patients. What we already know is that many patients who developed severe TR years after MV replacement for rheumatic MV disease had tricuspid annulus $<40 \mathrm{~mm}$ in diameter at the time of surgery. Thus, performing TVA whenever there is moderate and severe TR or a tricuspid annulus diameter $\geq 40 \mathrm{~mm}$ does not entirely prevent new functional TR. Furthermore, other factors play a role in its development. Longstanding atrial fibrillation is 1 of those factors.

Are patients who undergo MV repair for degenerative disease of the MV likely to develop functional TR if there is only trivial or mild TR before surgery? We are certain that some patients do, but it does not appear to be as common as in patients who undergo MV replacement for rheumatic disease. Is it solely because the incidence of atrial disease?

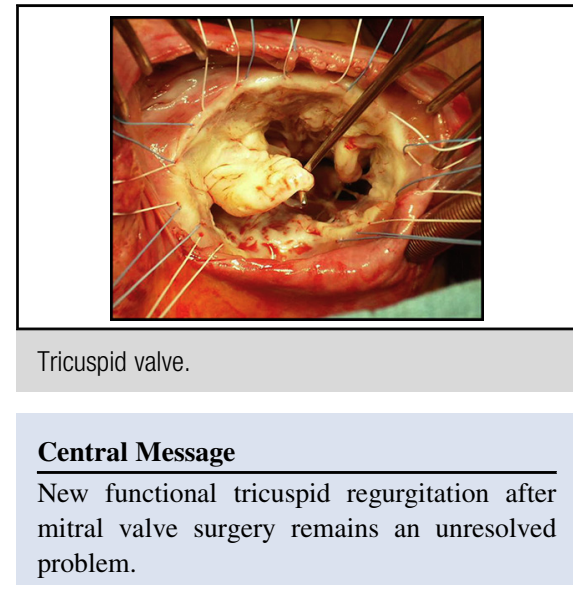

See Article page 1040.

fibrillation is higher in patients with rheumatic heart

We have been repairing MVs for degenerative disease for more than 3 decades and we have followed patients prospectively with echocardiography. ${ }^{2,3}$ When we first started repairing MVs for degenerative disease we believed that only severe TR should be addressed at the time of surgery. ${ }^{2}$ Thus, in a series 841 patients undergoing operation from 1985 to 2004 the proportion of patients who had concomitant TVA was $3.7 \%$. $^{2}$ During a mean followup of 10.4 years (with periodic echocardiograph studies) we found that 38 patients had moderate-to-severe or severe TR and 78 had moderate TR at some time, including patients who died. Influenced by the experience of Dreyfus and colleagues ${ }^{1}$ we adopted a more aggressive approach and began to address moderate TR at the time of MV repair. $^{3}$ Indeed, the proportion of TVA at the time of MV repair in our practice doubled. ${ }^{3}$ In a recently study on MV 